\title{
Image Technologies for Formatting Relations Between Russian and Belarusian Youth in the Post-Soviet Space
}

\author{
Natalya V. Shalygina, Irina A. Snezhkova* \\ Institute of Ethnology and anthropology named after N. N. Miklukho-Maklay Russian Academy of Sciences, Moscow, \\ Russia \\ ${ }^{*}$ Corresponding author. Email: snezhkova@ mail.ru
}

\begin{abstract}
The article is devoted to the consideration of new technologies for influencing the consciousness of Russian youth in the process of forming the image of both their country and other countries of the post-Soviet space. The most relevant example for considering the issue should be considered the situation with the development of integration processes between the Russian Federation and the Republic of Belarus, which have been going on for more than 20 years. A new generation of young people with a new mentality and value-oriented hightech era has grown over this period. The attitude of new youth (millennials) towards integration processes in the post-Soviet space requires other technologies more appropriate to the era; Priorities are those technologies that can take into account the youth's tendency to visual perception and the possibility of convergent media reality.
\end{abstract}

Keywords: image, post-Soviet space, youth, integration processes, convergent media space, mentality, technology

\section{INTRODUCTION}

The problem formulation. The three decades that have passed since the collapse of the USSR have outlined many new problems related to the search for mutual understanding and cooperation between the former Soviet republics. Today, Russia is pursuing a multidirectional policy towards each of the republics, striving to build a long-term policy of good neighborliness throughout the post-Soviet space. Despite all the existing problems of a political, economic or sociocultural nature, this process continues to develop in a progressive direction, uniting the interests of already sovereign states.

The policy of creating a positive image of the former Soviet republics in the eyes of new generations is one of the most effective mechanisms for establishing constructive mutual understanding in the post-Soviet space. Such a formulation of the question is of particular importance for Russia and the Republic of Belarus. The relations of the Russian Federation and the Republic of Belarus from the very beginning of their independence status in 1991 were formed as friendly and oriented towards the creation of a union state. The Treaty of GoodNeighborliness and Friendly Cooperation was signed on February 21, 1995. The Treaty on the Creation of a Union State of Russia and Belarus was signed on April 2, 1997 on the basis of the Community of Belarus and Russia, combining humanitarian, economic and military spaces. The agreement noted that the prospects for the development of the Union would be a consistent, voluntary association of the two participating countries. The charter of the Union was adopted on May 23, 1997. The Charter contains a mechanism for the functioning of this association. The defense ministers of Russia and Belarus signed the Agreement on the joint provision of regional security in the military sphere and the Agreement on military cooperation on December 19, 1997. The agreement on the creation of a unified energy system in Russia and Belarus was signed on November 21, 1999. After a long preparation, the Treaty on the creation of the Union State of Russia and Belarus was concluded on December 8, 1999. Since January 2000, the Union State became the official name of the Union. However, the Union State of Russia and Belarus still does not have a confirmed international legal status despite the successful cooperation of two sovereign states in the promotion of allied agreements.

Relevance of the topic. The uncertainty of interstate relations between Russia and Belarus at the present stage of their development creates a situation of tension that affects the most diverse areas of social life in both countries. The older generations born and raised in the USSR still retain the memory of a shared history and common heroic past, such as victory in the Great Patriotic War, economic recovery in the post-war years, the development of Soviet culture, etc .; and generations born 
after the collapse of the Soviet Union no longer have such a historical memory. For 30 years, the youth of Russia and Belarus have been taught to perceive a neighboring country as a foreign state, living its own life, shaping its own values, having the unconditional right to choose geopolitical landmarks, etc. Today, young people in the high-tech era of the twenty-first century are regarded as the most significant resource for the strategic development of both countries; therefore, the question arises of how and to what extent the new generations that have grown up under the conditions of "separation" are ready to continue the integration policy that began more than two decades ago.

Purpose of the study. This article presents a comparative analysis of image formatting technologies in the minds of post-Soviet youth in Russia and Belarus in the image of neighboring countries that were part of a single state until 1991. As far as the mechanisms of perception by the young generations of the former Soviet republics will be able to understand today, the strategy of further interaction between Russia and the Republic of Belarus in a new geopolitical reality will be just as promising.

Research task. The specific objectives of the study include consideration of modern image technologies that can create in the minds of new generations a particular image of their and neighboring countries:

1. City identity (street art projects)

2. Convergent media reality

3. Multimedia modeling

Hypothesis. The use of modern image technologies is focused on the clip consciousness of young people and is aimed at the formation of diverse ideas about the country (both its own and its neighboring one).

Methodology. The article uses an interdisciplinary approach combining sociological, psychological and anthropological theories. The gradual expansion of the range of problems associated with modern youth requires an appeal to new scientific paradigms that can provide explanatory models for empirical material accumulated over decades. As the dynamic complexity of post-Soviet society has increased in both Russian and Belarusian sociology since the beginning of the 21 st century, theories of the so-called integral metaparadigm have been especially demanded, explaining social development from the standpoint of cultural pluralism and offering for its understanding the simultaneous use of the most diverse and seemingly incompatible levels of analysis. The principle of nonlinear consideration of social phenomena that underlies integral analysis combines theoretical areas such as neopositivism, structural functionalism, a number of radical critical theories, conflict theories, etc., which are neoclassical (T. Parsons, P. Sorokin , R. Darendorrf, R. Collins, C.R. Mills, F. Alexander, G. Marcuse and others).

All such theories for post-Soviet sociology are an opportunity to explain the ambiguous and unequal processes of the formation of new identities in the territory of the former USSR, identities that today combine unreflected ideological constructs, social contradictions, ethno-political confrontations, value gaps and many other markers that characterize the new postSoviet reality. The particular difficulty in understanding this reality lies in the fact that it combined not only the consequences of global geopolitical transformations, but also qualitative changes at the technological level that are taking place in the modern world. In this regard, the identity of new generations born in such a difficult era cannot be regarded as a one-dimensional phenomenon, reflecting only one of the many challenges of the external environment. Due to their organic involvement in the multidimensional information space of the global world, young people are more likely to collect almost all dynamically arising challenges and develop qualitatively different reactions compared to older generations, and form new patterns of behavior that are appropriate to the changing era.

From the standpoint of psychological science, such theoretical paradigms as the psychology of image and the social psychology of the masses are used when considering the problem.

\section{METHODS OF THE STUDY}

The information that served as the basis for writing the article can be divided into several categories. A joint study of teachers of the Belarusian State University (BSU) and researchers at the N.N. Miklukho-Maklai Institute of Ethnology and Anthropology of the Russian Academy of Sciences (IEA RAS), conducted during 2018 - 2019, should obviously be considered the most informative source. The main methodological tool for this study was a questionnaire, which included 40 questions relating to topics such as stereotypes of perception of a neighboring people, identification of symbols of two countries, awareness of the similarities and differences between Russians and Belarusians, the degree to which students of Russia and Belarus are informed about each other from the point of view cultural features, an assessment of historical events during the existence of both countries within the USSR, an understanding of the processes of formation of the image characteristics of the country, etc. A total of 1000 students were able to cover the questionnaire: 500 people at the Belarusian State University (BSU) and 500 people in several Russian universities in Moscow. So, the survey was conducted in Moscow universities such as N.E. Moscow State Technical University Bauman (MSTU named after N.E.Bauman); Moscow Engineering Physics Institute (MEPhI); Institute of Journalism and Literary Creativity (ILLT); Russian State University for the Humanities (RSUH); Institute of Social Engineering of the Russian Humanitarian University named after A.N. Kosygina (ISI RSU); Moscow Finance and Law Academy (IFLA); Moscow Technical Institute of Communications and Informatics (MTUCI); Moscow State University of 
Technology and Management named after K. G. Razumovsky (PKU).

Another questionnaire, which included not only clarifying questions on the topic, but other forms of questions (filter questions, leading questions, direct questions, dichotomous questions, menu questions, closed questions) became a tool that ensured that the research group reached the most truthful answers with side of the respondents. The same version of the questionnaire included drawing tests, which belong to the category of projective techniques and are widely used, including in the ethnopsychological research practice. Projective techniques are based on incentives designed so that the respondent is forced to invest in them some meaning or interpretation. Due to this, projective tests bypass three main barriers to the study of human motives and attitudes: psychological repression, rational control and control of social influences.

In addition, a modified test by $\mathrm{M}$. Kuhn and $\mathrm{T}$. McPartland "Who am I" was used as part of an additional survey. This test was developed by these authors in the middle of the last century as part of the direction of symbolic interactionism (Chicago School); this test gives an idea of the features of personal self-identification of modern students, including gender, civil and ethnic parameters [1]. The use of the test by M. Kuhn and T. McPartland contributed to the identification of tolerance / intolerance of Russian and Belarusian students in relation to each other as carriers of a different ethnicity.

\section{DISCUSSION}

Fundamental research on the country's image in Russian science began in the early 2000s; they were justified by the need for a country to acquire the status of a strong state, lost in the 1990s. The basis for creating and promoting a new image of Russia in the international arena was supposed to be based on the advertising and communication technologies tested in the competitive environment of the market economy, and, first of all, branding technologies [2]. The idea of branding the state, developed by the English advertising patriarch David Ogilvy back in 1950-1960, looked like a three-stage scheme based on sociological studies clarifying the "weaknesses" of the existing image of the state, the subsequent development of a holistic concept of its most attractive values and the creation of on this basis, a general positive background, without highlighting any one side of the country's life. A similar scheme in the second half of the last century was successfully tested in the USA, Great Britain, Spain and other countries, increasing their attractiveness not only for tourists, but also for the population of these countries, especially young generations, who formed their own self-identification [3]. The study of factors that can influence the creation of a positive image of their country in the eyes of Russian youth began to be actively conducted only in the second half of the 2000s. From the point of view of the sociologist Gorbushina OP, Russian youth, like the youth of many other countries of the modern, high-tech era, are less prone to existing stereotypes, primarily because of their "social infantilism" and clip consciousness, devoid of any deep historical -cultural reflection. Therefore, the most effective communication channel that shapes the perception of the country's image by Russian youth is mainly an assessment by the media, which is often opportunistic in nature [4].

The aim of the study of Altai sociologists S. Maximova and Kaiser N.Yu. within the framework of the work "Russia between East and West: the image of the country in the social representations of modern youth", the study of the Eurasian image of Russia as a state by Russian youth was carried out. An analysis conducted by Altai sociologists showed that the holistic image of Russia in the views of young people in the Altai Territory conditionally breaks down into four blocks: "The Image of Russia in the Present", "The Image of Russia in the Past," The image of Russia in the future", "The Ideal Image of Russia". According to the results of a study by Maximova and Kaiser, the ideal image of Russia, which Russian youth, first of all, understands as the positive dynamics of per capita income, is of greatest importance in the minds of young people. The past of Russia is associated with the victories and conquests of the Russian people, the present and future are associated with the formation of the country's economic and political stability [5].

At the beginning of the second decade of the 21st century, Russian sociologists based on the Siberian Institute of Management, a branch of the Russian Academy of National Economy and Public Administration, conducted a similar study on the assessment by Russian youth of the prospects for the development of their country as a whole. The main conclusion was that most of the students (the general sample was 1,200) felt anxiety, fear, shame, their own helplessness before what was happening in Russia, and did not count on the help of the state. It was also concluded that the degree of students' moral readiness to take responsibility for the fate of Russia is low [6].

Thus, the image of Russia in the eyes of new generations of the country, for a long time, had rather negative connotations than positive ones. However, the events of 2014 related to the annexation of Crimea to the Russian Federation changed the attitude of Russian youth to their own state and caused a wave of patriotic sentiments among the majority of young generations, which also influenced their ideas about the new image of Russia. The most revealing in this sense were surveys of users of Runet social networks and, in particular, telegram channels popular among young people. If we consider that the telegram environment is the most liberal, pro-Western "party", the results of a survey of representatives of this environment regarding the attitude of young people to the annexation of Crimea should obviously be taken as the most convincing evidence of Russian youth's support for 
the state policy of their country: $68 \%$ of respondents said that they consider Crimea an integral part of Russia [7]. According to a survey by the Media Technologist channel in $2018,95 \%$ of the entire audience of the telegram environment confidently replied that the accession of Crimea to the Russian Federation in 2014 was "the restoration of all justice, the rescue of Crimeans, a great moment in history". The option "this is annexation, violation of international law" was chosen by only $5 \%$ of the "telegram" audience. In March 2019, the Levada Center research center, according to the Russian news agency Interfax, published the results of its own survey among young Russians, conducted in 137 settlements of the country, regarding their attitude to the annexation of Crimea to Russia. The results were no less convincing: $86 \%$ of respondents supported the reunification of Crimea and Russia. In addition, $70 \%$ of the respondents who participated in this survey believe that Russia did not violate international law when the Crimea peninsula became part of the Russian Federation [8].

Fundamental work on the dynamics of perception by the Russian youth of the image of their country in the new geopolitical conditions is clearly not enough today. However, research works that would provide a comparative analysis of the problems of perception by the Russian youth of the image of neighboring countries, which once constituted a single post-Soviet space, have until recently been practically not carried out at all in domestic social sciences. Although this context today is becoming more and more relevant, given the trend towards economic and political integration of the former Soviet republics.

\section{RESULTS}

The results of a comprehensive study conducted by the N.N.Miklukho-Maklai Institute of Ethnology and Anthropology RAS (IEA RAS) in conjunction with the Belarusian State University in 2018-2019 showed that all the most effective technologies that can form a positive attitude of young generations towards neighboring countries post-Soviet space, belong to the category of socalled "soft power". According to the definition of the American political scientist J. Nye [9], "soft power" is a form of power that provides the desired results based on the sympathy and attractiveness of the country's characteristics, which radically distinguishes "soft power" from "hard power", which implies coercion. The wording of "soft power" has also transformed as the geopolitical situation in the world changes, and today this expression means not only a demonstration of an attractive lifestyle as a competitive advantage of one country over others, but also the country's ability to cooperate in certain areas based on mutually beneficial conditions.

The main elements of "soft power" are considered culture, science, an effective educational system, that is, everything that creates an attractive image of the state in the eyes of both its citizens and citizens of other countries. According to some Russian researchers, the potential of "soft power" possessed by Russia is used unsystematically and does not have a clearly formulated goal [10]. Nevertheless, the results of our study showed that those "soft power" resources that modern Russia possesses are quite effective in the process of forming mutual understanding of the youth of Russia and Belarus.

The basis for the development of Russian resources for the use of "soft power" in relation to partner countries, the study showed, is, first of all, the factor of a unified mentality of young people, formed in the high-tech, "IT" era of information communications. In the process of the study, the theory of generations developed in 1991 by American researchers W. Strauss and N. Howe was used, which examines the most characteristic features of modern youth in Russia and Belarus, born already at the end of the twentieth century - the first decade of the twenty-first century, and this generation called millennials [11].

Belorussian and Russian millenials, possessing features common to the whole generation of world perception (video consciousness, technological advancement, accelerated pace of life, lack of reflection, social emancipation, rejection of team spirit, priorities of "horizontal development", etc.), differ in their own characteristics that have formed already in the post-Soviet era and reflecting the national specifics of both countries [12].

For example, the image of Russia in the minds of Belarusian millennials in recent years has noticeably lost a clear value contour; it increasingly began to give way to the so-called collective image of the West in some regions of the country.

Nevertheless, the results of our sociological study of student youth in 2018-2019, allow us to draw an optimistic conclusion not only about restoring mutual understanding between Russian and Belarusian youth, but also about the successful development of their cooperation in many areas of joint management in the coming years. The main reason for this optimism is the fact that the millennial mentality provides for the gradual blurring of borders between countries and continents, between races, nations, frontier markers and other artificial "dividers" that exist in the modern world.

Web visualization. The virtual communication format in which the millennials "live" does not recognize boundaries that retain their original significance only in the plots of their computer games [13]. In the course of our comprehensive study, an analytical assessment was given to some forms of Internet visualization of fan art in social networks, which can be considered an innovative approach to the study of youth perception of the country's image. Forms of Internet visualization such as Countryballs and Humanization were considered. The format of Countryballs ("Country-balls") is an image of various countries in the form of balls, or balls, which are painted in the colors of national flags and also have some 
attributes characteristic of a country. The presence on the balls of the eyes endows them with the functions of certain living creatures that play various scenes of a political nature in a humorous genre and thereby reproduce relations between states or peoples.

An analysis of the fanatical Internet creativity of Belarusian youth in Countryballs style allows, for example, to draw conclusions that the creators of such visualizations are supporters of the independence of their country and recognize a purely individual way of its historical development. In addition, the analysis of stories in the style of mapping (that is, playing historical events on the map with the help of "balls") makes it possible to conclude that Belarusian youth perceives Russia's political position in Europe as dual: on the one hand, according to the Belarusian From the point of view, Russia seeks to revive the Soviet Union, but, on the other hand, is the initiator of a kind of international reconciliation, which is possible (according to mapping plots), including due to the balanced and neutral position of Belarus.

Internet visualization in the style of Humanization is the assignment of anthropomorphic features to countries and the creation on this basis of anime plots with personalized heroes. The "humanization" of three Slavic countries neighbors in the territory of the post-Soviet space (Russia, Ukraine and Belarus) translates into a plot about the relations of an older brother (Russia) with two sisters (Ukraine and Belarus), which were greatly complicated after all the characters left their common House (USSR). Ukraine, the eldest of the sisters, has already made a mistake by making friends with America; Belarus, the younger sister, is rushing between the irresistible love for his brother, even reaching the desire to marry him, and the desire to follow his own character, which is endowed with sufficiently pronounced features of national pride as depicted in the "cartoons" [14].

City Identity. Another option for influencing the youth's consciousness in the format of "soft power" in the process of research was considered using the example of urban identity (or urban street art projects). The territorial identity of the city (decorating the facades of houses, creating images in the format of public and street art, etc.), as a rule, is created by young people and reflects the youth

Table 1 Priorities of the Belarusian youth media audience in choosing the main sources of mass political information in 2018 (in \%)

\begin{tabular}{|l|l|l|l|l|l|l|l|}
\hline Thematic field & $\begin{array}{c}\text { Newsp } \\
\text { apers }\end{array}$ & Radio & TV & Internet & $\begin{array}{c}\text { Social the } \\
\text { network }\end{array}$ & $\begin{array}{c}\text { Friends, } \\
\text { Relatives }\end{array}$ & Total \\
\hline 1. Policies & 2,7 & 3,3 & 18,7 & 50,3 & 17,9 & 7,1 & $100 \%$ \\
\hline 2. Economics & 1,1 & 1,4 & 17,1 & 54,6 & 18,8 & 7,1 & $100 \%$ \\
\hline 3. Cultural life & 1,6 & 1,4 & 13,4 & 43,6 & 34,5 & 5,5 & $100 \%$ \\
\hline
\end{tabular}

Thus, Belarusian youth is almost completely included in the network space, and auditory receptors (radio) and traditional linear printed text (reading a line from left to

traditional linear printed text (reading a line from left to perception of their city and their country. The relevance of this format is that street art projects are increasingly becoming the battlefield of various ethnic and political positions, ideological beliefs and value systems in general. In the language of street art, young people not only express themselves, but also express their attitude to events taking place in the world, including the development of the idea of the Russian-Belarusian state [15].

The question of which of the areas of mass art can be attributed to street art and how it should be perceived today causes a lot of controversy and discussion, including in the blogosphere of Runet. One of the most common opinions is that modern youth art street is the direction of the underground, i.e. riot, protest against any mainstream, including formally permitted art. However, another opinion is becoming more and more popular in the blogosphere that qualifies street art (due to its rapidly gaining political engagement and, accordingly, commercialization) as one of the varieties of the mainstream itself, which revolts "against another mainstream" [16]. To some extent, the opposition of positions on this issue reflects the complexity of today's processes of formation of the youth mentality as a whole, but at the same time creates a discussion platform in the style of "soft power".

One of the most important tools for influencing the youth's mind with the help of "soft power" can be considered the use of the capabilities of the so-called converged media, or the information mechanism that combines the efforts of traditional media and new media. [17]. This mechanism is otherwise called "multimedia," "interactive," "as visualized as possible," etc. The term "convergence" means the convergence, the merger of various media platforms [18]. In the course of our study, data were obtained that indicate a reformatting of the structure and content of the information field from traditional media to network resources. It was revealed that the classical sources of mass media (radio and print media), for example, are not actually used by the Belarusian youth audience.

right), which provides television, are not involved. In turn, the maximum use is made of the visualization of information, the speed of searching for the necessary 
information, the ability to be the source of reproduction and distribution of the media (social media)" [19]. Thus, we can conclude that the information environment in new media will be an effective tool for forming the opinions and attitudes of young people, in particular, opinions and attitudes regarding the Union State of Russia and Belarus now and in the near future.

Prospects for cooperation between Russian and Belarusian youth. In 2017, a presentation of the statistical study "Integration Barometer" was held at the Federation Council of the Russian Federation. It was based on sociological polls conducted by such authoritative sociological services as the Russian VTsIOM, the Donetsk Information and Analytical Center and the Belarusian Novak Center. 1,600 young people under 30 in Russia and 1,062 people in Belarus were interviewed in a representative sample. It was supposed to clarify the attitude of Russians and Belarusians towards the prospect of cooperation and integration of the two states. An analogue of the project was the Eurobarometer, a study that has been conducted in the EU countries twice a year for more than 30 years [20]. The vast majority of respondents answered that there are grounds for rapprochement between the two peoples, and only $6 \%$ of respondents from Russia and 10\% from Belarus stated that there are no grounds for this. The main "points of contact" between the two peoples, according to the respondents, are the common historical past, family ties between the inhabitants of these countries, the coincidence of economic interests (22 to $42 \%$ of respondents noted these positions). If the common historical past is in the first place for Russia, then the commonality of economic interests leads in the responses of residents of Belarusian youth. The "second plan" of rapprochement between the two Slavic peoples is the proximity of culture, language and the political component of integration - the coincidence of the political interests of the countries and the will of their leaders (8-19\% of respondents noted these positions). Moreover, cultural, linguistic proximity turned out to be more important for Russians than for Belarusians, while the latter more often emphasized political interests.

The difficult situation associated with the integration processes necessitated a more substantive study of the views of the youth of the two countries regarding the prospects for building the Union State. A study conducted in 2017 by the Research Center for Integration Problems of the Eurasian Economic Union Member States "Union Narrative 2050" ("Sonar-2050") and called "Generational Change and the Future of Public Opinion on Union Integration", consisted of three blocks of issues - political, economic and sociocultural sympathies. In the first block, states were determined that, according to the respondents, are friendly or, on the contrary, not friendly with respect to their country of residence. In the second economic block, questions were raised about the interest of different generations in developing trade, attracting investments, borrowing technologies, developing a common labor market, etc. Finally, the third block, reflecting the sociocultural attraction of the peoples of both countries, assessed how much the peoples of these countries are attractive to each other in terms of studying culture, history, tourism, study, etc. [21].

Regarding the political block of issues, we can say that the definition of Belarus as a friendly state in Russia did not reveal a noticeable difference in opinions between generations; $65 \%$ of all respondents called the country friendly. In Belarus, the share of respondents who consider Russia a friendly state is $82 \%$, but the difference between generations is much more noticeable. So, if up to $85 \%$ of respondents show friendliness in the older and middle age groups, then among the 20 -year-old youth representing the millennial generation, they turned out to be less, about $73 \%$.

The gap between generations can be traced in Russia. So, on the question of the country's preference for a potential relocation, $47 \%$ of Belarusian youth would choose the European Union or other Western countries. It is noteworthy that such a choice would be made by about $30 \%$ of millennials in Russia. Among the older generation, these indicators are even lower - $18 \%$ of respondents in Belarus and $10 \%$ in Russia. CIS countries would choose only $9 \%$ of the Belarusian youth as an alternative place of residence, but $25 \%$ of the Russian youth. This share of young Russians practically coincides with the share of the older generation of Russians, in terms of sociological analysis.

As for the reverse process, that is, the transfer of foreigners to work and study in Belarus and Russia, there is a more uniform picture with the expressed interest of respondents in Western countries. More than $60 \%$ of millennials and approximately $50 \%$ of older generations in Belarus would like to see specialists and students from the European Union and other countries in their country, while residents of the CIS and Russia are only $27 \%$ and $30 \%$ respectively. A similar picture, according to the results of studies of the sociological research SONAR2050, is observed in Russia.

Even more important results for understanding the future of Russian-Belarusian integration were obtained when Russian and Belarusian youth answered the question about which countries should first of all collaborate in science and technology. Provided that it was possible to choose several countries, it turned out that $55 \%$ of Belarusian youth see the EU as partners in science and technology, and about $70 \%$ are other countries, primarily the United States and Japan. The CIS and Russia in this regard are called about $44 \%$. As for the older generation, the respondents' opinions were distributed as follows: $53 \%$ would like to cooperate with specialists from the CIS countries and Russia, and $49 \%$ and $56 \%$ would choose, from this point of view, the European Union and the rest of the world, respectively.

Thus, the share of Belarusian millennials who prefer to cooperate with their colleagues from the CIS countries significantly exceeds the similar indicator among Russian 
millennials, which, apparently, can become one of the incentives in the negotiation process about the future of the Union State.

\section{FINDINGS}

The following conclusions were made as a result of the study.

1. The youth of Russia and Belarus, having a common mental foundation for the generation of millennials, have a good enough resource to establish mutual understanding in the near future. Despite differences in views on the potential of allied relations, noted by some Belarusian students; The focus on cooperation with Russia in the field of high technology, science and technology has already been formed among at least $50 \%$ of Belarusian youth.

2. Joint Russian-Belarusian projects aimed at young generations are the most promising image technology of "soft power" for forming the information and cultural basis for the integration of the two states. Projects aimed not at forming or strengthening economic and cultural ties, but at building a new union identity, are particularly effective.

3. An equally important format for using "soft power" in creating a positive image of a partner country for new generations of Russia and Belarus is Internet visualization in Runet social networks. The distribution of game stories in the network, lowering the status of union integration of the two countries due to negative images, with each new generation leads to a decrease in the supporters of this integration.

4. Street art as a format of "soft power" is one of the options for the formation of youth identity in an urban environment. This type of visual impact, which is most perceived by modern youth, combines the territorial branding of their country with the ideological constructs of a union state, without acting as a propaganda tool.

\section{CONCLUSION}

Modern image technologies used in formatting youth relationships in the post-Soviet space have qualitatively new characteristics that take into account the mentality of new generations. The peculiarities of the youth mentality of the information age include clip consciousness, the priority of visual perception, technological advancement, an accelerated pace of life, socio-political freedom, the preference for virtual communications over live communication, etc. All of these and similar qualities of youth are taken into account by such technologies of "soft power" as plots of Internet visualizations in Runet, urban identity and the creation of a converged media space in general, combining both traditional and innovative forms of delivering media information.
Visualization of any object of attention of new generations born already in the era of Internet technologies makes it possible to more quickly and more organically assimilate information. The perception of a picture is more complete, compared with verbal text, transforms in millennials into figurative-semantic constructions and forms a plan of active activity for them. Moreover, the modern capabilities of multimedia visualizations initiate interactive modeling of the most unexpected situations, liberating the consciousness of young people and freeing them from stereotypes of behavior. Multimedia modeling of the country's image in the network space allows millennials to catch unobvious associations, place accents and find original solutions where older generations are often powerless. The use of this kind of image-building technologies in relation to new generations of young people allows us to count on the fact that their perception of the post-Soviet space and, especially, relationships among themselves in this space will receive a new, positive impetus for their development.

\section{ACKNOWLEDGMENT}

The article was written as part of the research work 2020 of the N.N. Miklukho-Maklai Institute of Ethnology and Anthropology of the Russian Academy of Sciences (IEA RAS)

\section{REFERENCES}

[1] M. Kun, T. MacPartland, An empirical study of personal attitudes toward oneself, Modern foreign ethnopsychology (1984)180-187.

[2] I. Rozhkov, V. Kismereshkin, Image of Russia. Resources, experience, priorities, RIPOL classic, 2008.

[3] D. Ogilvy, On advertising, Eksmo, 2007.

[4] O.P. Gorbushina, The image of the country among Russian youth: structure and formation factors: structure and formation factors, 2006.

[5] S.G. Maksimova, N.Yu. Kaiser, Russia between East and West: the image of the country in the ideas of modern youth, News of Altai State University 2 (58) (2008).

[6] O.V. Kuzmen, Present and future of Russia in value orientations and ideas of students, Monitoring of public opinion: economic and social changes 6 (118) (2013) 139-147.

[7] The real attitude of Russians towards the annexation of Crimea has been clarified, Available at: 
https://newstut.ru/vazhnye/223038-vyyasneno-realnoeotnoshenie-rossiyan-k-prisoedineniyu-kryma.html.

[8] The survey showed the attitude of Russians towards the annexation of Crimea, RIA Novosti, Available at: https://krym.news/news/politics/staloizvestno-otnoshenie-rossiyan-k-prisoedineniyu-kryma/.

[9] J.S. Nye, Bound to Lead: The changing nature of American power, 1991.

[10] A.O. Naumov, "Soft power" and the foreign policy image of the Russian Federation, Prospects 4 (2015) 21-32.

[11] N. Howe, W. Strauss, Generations: The History of America's Future, 1584 to 2069, William Morrow \& Company, 1991.

[12] N.V. Shalygina, Communicative features of new generations, Modern youth and society, In the dialogue of countries and cultures: historical experience and modernity 7 (2019) 11-17.

[13] D. Volkov, S. Goncharov. Russian media landscape 20, Levada Center, 2019, Available at: http://docplayer.ru/162902911-Analiticheskiy-centryuriya-levady-rossiyskiy-media-landshaft-2019televidenie-pressa-internet-i-socialnye-seti.html.

[14] R. Hoysling, Social processes as network games, Sociological essays on the main aspects of network theory, 2003.

[15] Kokhno, "A good gift" or "Some kind of propaganda"? Graffiti about the friendship of Minsk and Moscow was opened in the capital, 2020, Available at: https://news.tut.by/society/499743.html.

[16] The engine of street art, 2015, Available at: https://ctyzyrka.ru/vizualnyj-salon/840-strit-art.

[17] BSU in numbers, 2019, Available at: https://bsu.by/ru/main.aspx?guid=284041.

[18] Multimedia journalism: a textbook for universities, 2017.

[19] A.V. Postalovsky, I.D. Rasolko, D.G. Rotman, Social Media in the Information Field of the Republic of Belarus, Journal of the Belarusian State University, Sociology 4 (2014) 95.

[20] A. Shustov, Barometer of integration, Will Russia remain a center of attraction for the countries of the former USSR? 2014, Available at: http://www.stoletie.ru/geopolitika/barometr_integracii_ 845.html.

[21] The key sociological threat to union integration is the reduction in the number of its supporters with each new generation, Available at: https://www.sonar2050.org/publications/smenapokoleniy-i-budushchee- obshchestvennogo-mneniyav-voprosah-soyuznoy-integracii. 